\title{
MOLTEN METAL FLOW ANALYSIS OF HOUSING COMPONENT
}

\author{
Bodhayana M.R. ${ }^{1}$, N Ramesha ${ }^{2}$ \\ ${ }^{1}$ Student, M.Tech in tool engineering, Govt. Tool Room and Training centre, Mysore 570016, Karnataka, India \\ 2lecturer, Department of PG studies, Govt. tool room and Training centre, Mysore 570016, Karnataka, India
}

\begin{abstract}
Die casting is a versatile manufacturing technique in which molten metal is poured into die. The die consists of core and cavity, an impression is formed when these core and cavity are closed together. This impression forms the shape and size of the component. The main challenge in die casting is design and manufacturing of die. Integration of design and analysis yields to better results. Die casting is often encountered with many problems, few of such problems are blowholes, improper filling, scratch marks, weld lines, cracks, cold shut, porosity, blisters, ejector pin marks, etc. usually these defects are caused due to improper design of dies, or due to incorrect parameters such as injection pressure, cycle time, cooling circuits and other such parameters. In order to eliminate such defects a set of analysis has to be carried to ensure that design and other parameters are safe and efficient. Through analysis is carried to understand how the molten metal behaves inside the dies once it is injected, a clear picture about how the molten metal gets solidified is obtained during analysis. Any defects if present can be studied by analyzing the results of analysis. In this paper pro cast analysis software is used for analysis purpose, the flow of molten metal inside the impression was studied and changes to be made to the design were analyzed. Behavior of molten metal at different stages of time such as temperature variations, pressure variations is studied. Different graphs are plotted to study the behavior inside the dies.
\end{abstract}

Keywords: Flow simulation, Solidification, Aluminum die casting, Pressure, Temperature analysis, Die casting, Procast.

\section{INTRODUCTION}

Die casting is a versatile process in which molten metal is poured in to dies which form the shape and size of the component. Die is made of steel, the inserts ejector pins and those parts which come in contact with the molten metal are made up of HDS (hot die steel) and heat treated to achieve good strength and tool life. Before starting the cycle the dies are applied with die coat. Then molten metal at $660^{\circ} \mathrm{c}$ (this temperature is recommended for aluminium) [1] is poured into the preheated die, the dies are usually heated to around $150-300{ }^{\circ} \mathrm{c}$. Preheating of dies improves the tool life. The machine plunger pushes the molten metal into the dies. This is followed by filling of molten metal in to the impressions, solidification and lastly ejection of component.

Analysis is an important part of die casting. It shows virtual activity inside the die, starting from air movement inside the die to molten metal flow. With the advancement in computer an effort is made to study the defects in the die casting as a consequence of physical phenomenon that are involved. A detailed modeling with improved description of physical processes has become more realistic and straight forward approach.

This paper details about Aluminium A380 which is the casting material, having shrinkage of $0.6 \%$, its melting temperature range is $557^{\circ}$ to $596^{\circ} \mathrm{c}$. Density of the A380 is $2.71 \mathrm{gm} / \mathrm{cm}^{3}$. Aluminium A380 must be melted to $650^{\circ}-660^{\circ}$ as it gives optimum results. If it is heated beyond $660^{\circ} \mathrm{c}$ aluminium gets oxidized. Below $650^{\circ} \mathrm{c}$ proper filling is not possible. The die material HDS (hot die steel) is heat treated to 48HRC. HDS obtains maximum hardness when heat treated to $48 \mathrm{HRC}$, heat treating it beyond $48 \mathrm{HRC}$ makes it brittle and the dies may easily break during the working.

\section{EXPERIMENT ANALYSIS}

Analysis of the part is done using Pro cast software. Analysis is done to determine the behavior of molten metal inside the die. The flow of molten metal plays an important role in component filling, the direction of flow shows the proper filling in dies[2], which gives an idea about possibilities of generation of blowholes due to porosity which intern helps us to decide the placement of air vents, chill vents, cold wells. Solidification analysis helps us understand how the molten metal gets solidified within the dies, which area solidifies first and this result helps us to alter the gating, runner arrangements. Temperature analysis helps us in designing cooling channels and cooling circuits. This analysis result helps in optimizing design and various process parameters. To obtain optimum results in this software, the number of input data must be provided correctly.

The main inputs to be provided for analysis are

1. Thermo physical properties such as density, specific heat, thermal conductivity, die material, and temperatures.

2. Boundary conditions such as die material heat transfer coefficient, feed aids including chills air vents.

3. Process parameters such as poring rate and temperature. 
Pro cast utilizes computer aided design (CAD) files for analysis. Pro cast based on finite element method (FEM) technology is able to predict flow of molten metal, temperature, and pressure variations, air movement, residual stresses and deformations. This software incorporates CAD data with FEM techniques to quickly and easily enable a virtual "what if" design before die construction. It also enables to optimize process parameters and die design.

\subsection{Component and Material Study.}

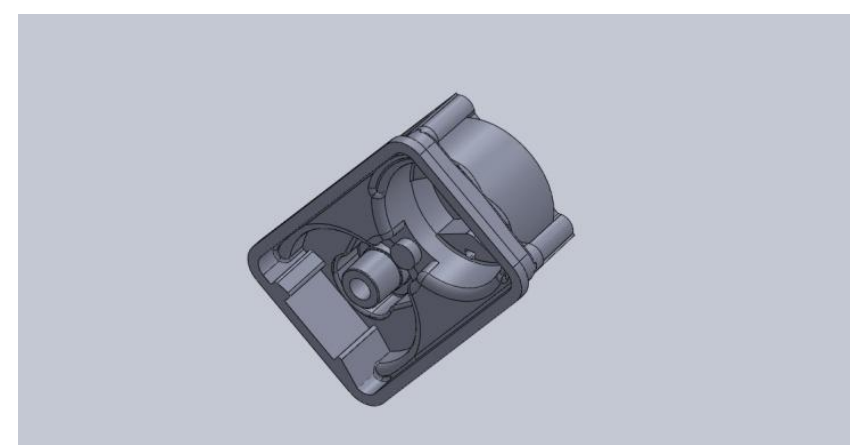

Fig 2.1.1

The component is known as housing component (CBA Housing according to industry). Housing component finds its application in diesel engines. It is used for housing of "diesel engine actuator housing". The component material is aluminium A380. A380 with a density of $2.71 \mathrm{gm} / \mathrm{cm}^{3}$ has good resistance to hot cracking, corrosion. A380 retains good strength at elevated temperature.

Table 2.1: Chemical compositions of A380 [3]

\begin{tabular}{|l|l|}
\hline Composition & Percentage \\
\hline $\mathrm{Si}$ & $7.5-9.5$ \\
\hline $\mathrm{Mg}$ & 0.10 \\
\hline $\mathrm{Cu}$ & $3.0-4.0$ \\
\hline $\mathrm{Mn}$ & 0.50 \\
\hline $\mathrm{Fe}$ & 1.3 \\
\hline $\mathrm{Zn}$ & 3.0 \\
\hline $\mathrm{Ni}$ & 0.50 \\
\hline $\mathrm{Sn}$ & 0.35 \\
\hline
\end{tabular}

\subsection{Air Entrapment}

Analysis was carried to study how the air inside the impression will flow when the molten metal is injected into the die. This is one of the important factors to be taken care of, if air is present inside the die it mixes with the molten metal and forms the weaker portion of the component. The air present inside the dies also generates blow holes, porosity. This leads to a weak component. Die casted components usually finds its scope in places which are subjected to high temperatures, pressures. This indeed faces high thermal stress. Components with blow holes and porosity, often fail in these situations.

A thorough analysis of part was made to check how the air travels out during the injection stoke. Results show that air is being pulled out by air vents, and there is no mixing of air and molten metal. Hence component is free from porosity and blow holes.

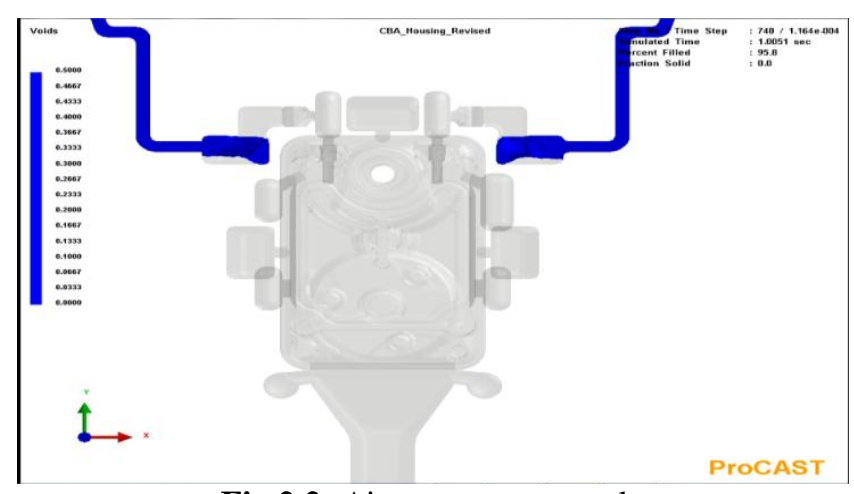

Fig 2.2- Air entrapment result

Fig 2.2 shows the air being pushed out as the molten metal advances.

\subsection{Pressure during the Injection Stroke}

Pressure is one of parameters which decided the component quality. Solidification of molten metal at high pressure increases the mechanical properties such as impact strength, tensile strength and hardness [4]. Material packing is one of main concern for component strength. Component will have higher strength and toughness when the metal is packed completely. This can be achieved when the pressure is optimum. As the pressure increases porosity decreases and pore size is shifted to smaller pores [5] Fine arrangement of molecules is achieved. Also if pressure is less, it leads to mixing of air and molten metal. Sufficient pressure is required to push the air out without mixing with the molten metal. Injection pressure must not exceed clamp force. Switch over pressure must be less than fill pressure to reduce flashing.

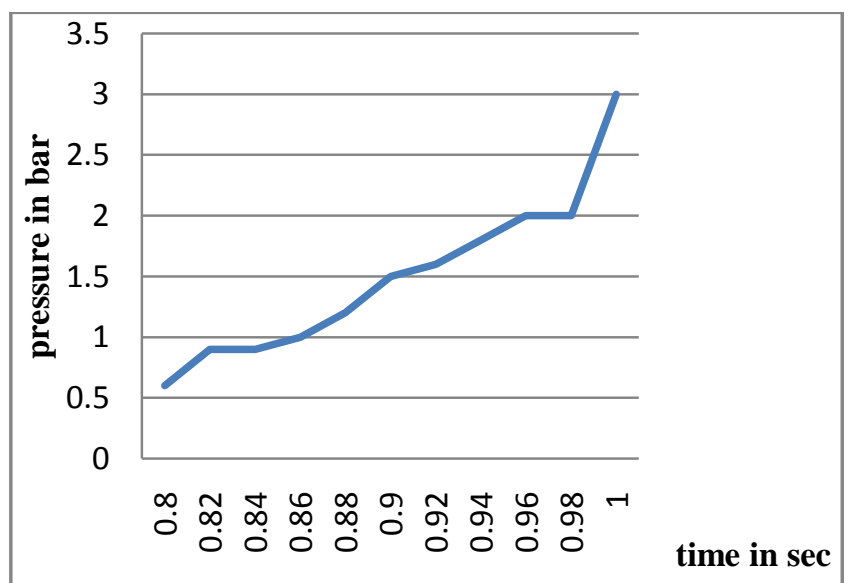

Chart 2.3 shows the pressure during different stages of filling.

Chart 2.3 shows the pressure variation during the injection of molten metal inside the die. Initially when the plunger is moving at a slow speed pressure is around 0.5 bars. As the molten metal fills the impression the pressure increases and during the final injection the plunger forwards at higher speed increasing the pressure to 3 bars. At 3 bars pressure the 
molten metal is being pushed and the component is filled completely. This chart also shows that at pressure of 3 bars final packing of the molten metal takes place. Hence it is deduced from the chat that optimum die filling pressure is 3bars.

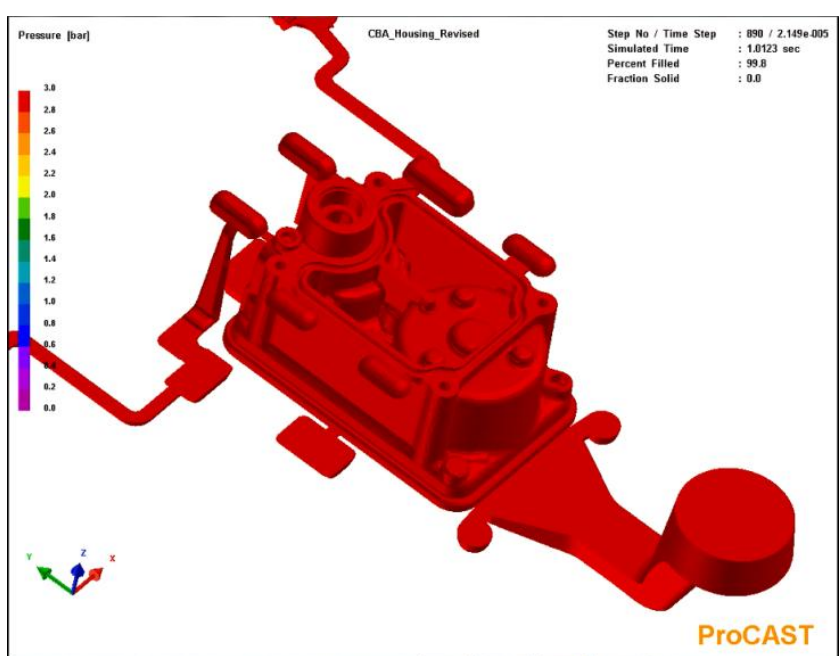

Fig 2.3 pressure when the plunger is completely pushed

Analysis results show that pressure of 3 bar is optimum for molten metal filling and at this pressure the component filling is good and quality of casting is good.

\subsection{Solidification of Molten Metal}

Molten metal inside the die gets solidified soon after it is injected into the die. Die has to be allowed in closed position for some time to allow this solidification. If the component is ejected before solidification, the component will not be proper and it will not attain its geometrical features.

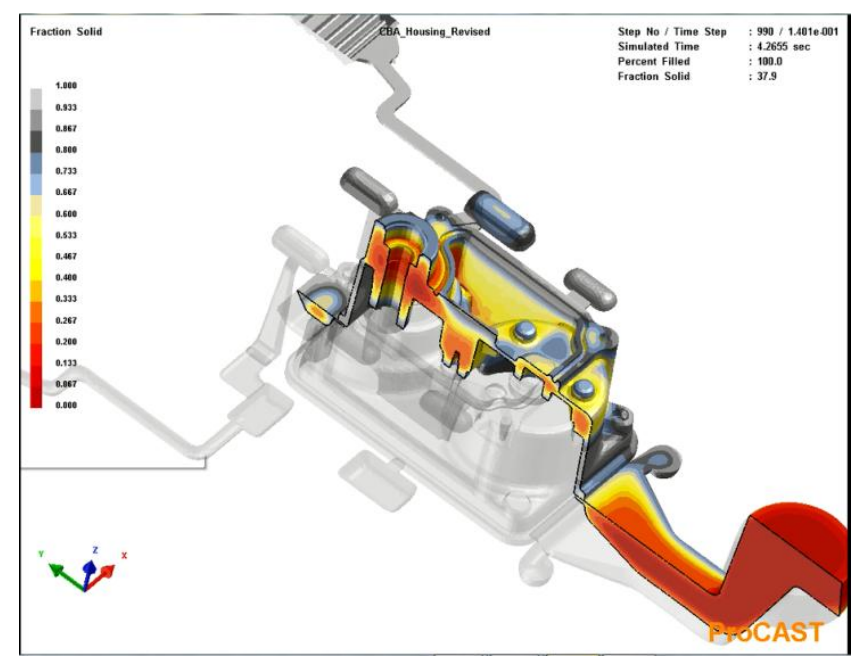

Fig 2.4

Fig 2.4 shows the temperature of the molten metal when it is solidifying. It is clear from the fig 2.3 that the runner, gates and overflows are solidified before the component metal is being solidified. In order to obtain an optimum design, first the runners and gates must solidify before the metal which forms the component solidifies. If the component solidifies before the gate then due to pressure difference the molten metal inside the component area will flow back to runner and sprue resulting in non uniform packing of the component.

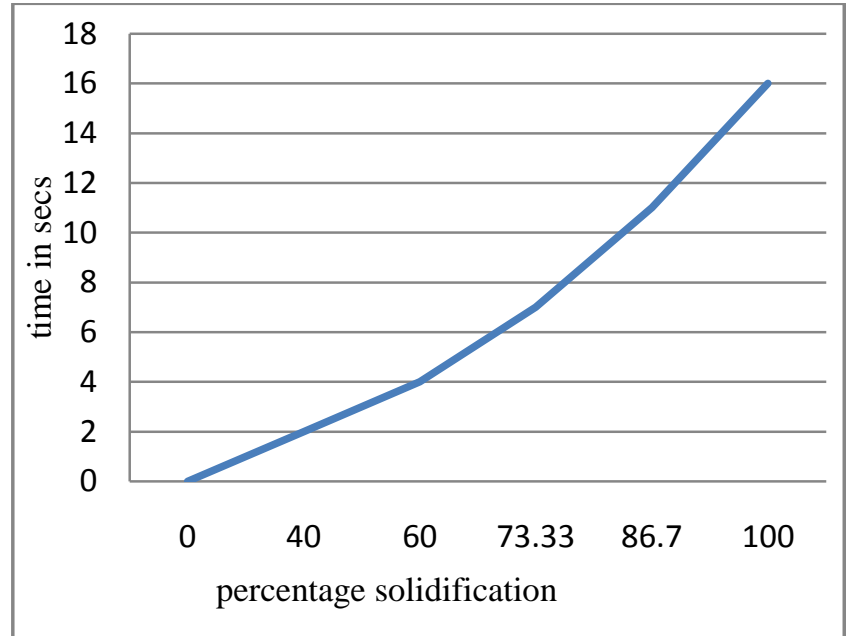

Chart 2.4

Chart 2.4 shows solidification with respect to time. The graphs also shows the time required for solidification of the component according to the results shown the component requires 16 seconds to solidify.

\subsection{Temperature Distribution during Component}

\section{Filling}

Temperature distribution in die casting is also important as it plays a vital role in deciding the quality of castings. The die is preheated to $250^{\circ} \mathrm{C}$ (usually in die casting dies are pre heated from $150^{\circ}$ to $300^{\circ} \mathrm{c}$ )[6]. Aluminium which is in the form of ingots is melted to around $650^{\circ}-660^{\circ} \mathrm{c}$. and molten metal at around $650^{\circ} \mathrm{c}$ is injected in to the die using plunger ( in case of hot chamber molten metal is directly fed into the dies) when the molten metal comes in contact with the dies which is at lower temperatures (around $250^{\circ} \mathrm{c}$ ) tries to cool down due to temperature difference. If the molten metal decreases below liquidious temperature $\left(590^{\circ} \mathrm{c}\right)$ the component will not be filled properly and chances of producing a defected component is high. In case of larger components where surface area is too large and time required for molten metal to reach the last point ( point away from the injection point) is too high, in these situations the molten metal before it reaches the last point may reduce to liquidious temperature hence care must be taken during designing of the dies. 


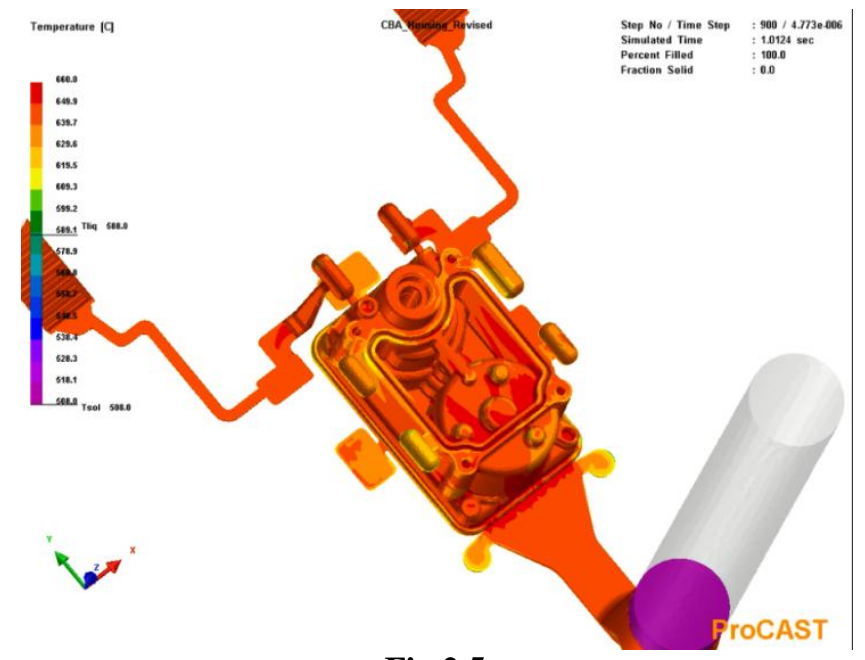

Fig 2.5

The above fig 2.5 illustrates the temperature of the component when the injection is completed i.e., when the component is completely filled. It shows that temperature is around $650^{\circ} \mathrm{c}$ inside the component. This shows that the component quality will be good.

\section{CONCLUSIONS}

1. Component is free from air entrapments. Overflows, chill vents design are best situated. Runner design and gate location and design are best situated.

2. Optimum die filling pressure is 3 bars.

3. Overflows will get sealed before the molten metal inside the impression which forms the shape of the component solidifies.

4. Injection of molten metal at $650-660^{\circ} \mathrm{c}$ results in proper filling and solidification of molten metal.

\section{ACKNOWLEDGMENTS}

Sincere thanks to SEEAAR Machine Tools Pvt. Ltd. For providing me an opportunity to carry out the paper work in there firm,

\section{REFERENCES}

[1]. T. Mounika, K.V.P. Chakradhar \& V. Srinivas vishwanath. Die designing and molten metal flow analysis of parking brake piston. International journal of Mechanical and production engineering research and development ISSN 2249-6890 VOL 3, Aug 2013, 99-108 published in TRANS STELLAR.

[2]. Kvenkatesan and $\mathrm{R}$ Shivpuri Experimental and numerical investigation of the effect of process parameters on the erosive wear of die casting die ASM International JMEPEG 1995 4:166-174

[3]. ASM data handbook, Vol. 2, tenth edition, ASM International, 1990, pp. 164-170

[4]. Richard Ford, Jessica Smith, Effects of pressure in the mechanical properties and Microstructure of die cast aluminum A380 alloy. Europian journal of mechanical engineering and manufacturing vol 112013 ISSN 26683172 ISSN

[5]. Z. Ming, Z Wei-wen, Z Hai-dong, Z Da-tong, L. Yuanyuan.: effect of pressure on microstructures and mechanical properties of $\mathrm{Al}-\mathrm{Cu}$-based alloy prepared by squeeze casting $(J)$ Transactions of non ferrous metals society of China 17(3):496-501, 2007.

[6]. Mohammad Sadeghi and Jafar Mahmoudi experimental and theoretical studies oon effect of die temperature on the quality of the products in high pressure die casting advences in Material science and engineering volume 2012, article ID 434605.

\section{BIOGRAPHIE}

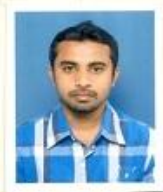

Bodhayana M R, BE mechanical Perusing M.Tech in tool engineering. 